\title{
DISPOSITIVOS DE NORMATIZAÇÃO DO ENSINO DE SOCIOLOGIA NA ESCOLA: FORMAÇÃO E SABERES DOCENTES DE LICENCIANDOS EM CIÊNCIAS SOCIAIS NO DISTRITO FEDERAL*
}

\author{
Sayonara de Amorim Gonçalves Leal ${ }^{1}$
}

\begin{abstract}
RESUMO: Este artigo trata de aspectos sociocognitivos e institucionais relacionados ao descompasso entre formação instrucional, saberes docentes e mediaçôes pedagógicas em Ciências Sociais expresso na prática docente de licenciandos e professores de Sociologia em escolas públicas e particulares do Distrito Federal do Brasil. Baseada em questionários, entrevistas semiestruturadas e análise documental, chegamos à seguinte tipologia de representaçóes de práticas docentes em Ciências Sociais: institucionalizadas, desconexas e propositivas. Inferimos que tanto os desafios como as perspectivas para a Sociolgia no ensino médio do Distrito Federal passam pelo equilíbrio entre transposição de conteúdos instrucionais adaptados ao perfil sociocognitivo do alunato e formação e saberes docentes dos professores que atuam em contextos escolares diversos e adversos.
\end{abstract}

Palavras-chave: Saberes e formação de docentes. Mediaçóes pedagógicas. Ensino de Sociologia. Escolas do Distrito Federal.

\section{TEACHING KNOWLEDGE AND PEDAGOGIC MEDIATIONS FOR TEACHING SOCIOLOGY AT SCHOOLS: A STUDY OF UNDERGRADUATES TRAINING IN SOCIAL SCIENCES AT THE UNIVERSITY OF BRASILIA}

ABSTRACT: This paper is about social, cognitive and institutional aspects related to the problem of the mismatch between the academic trajectory, teaching knowledge and pedagogic mediations in Social Sciences expressed in the teaching practice of teachers and bachelors in Sociology working in public and private schools from the Brazilian Federal District. Based on questionnaires, semi-structured interviews and documental analysis, we reached a typology of representations of teaching practices in Social Sciences,

\footnotetext{
*Esse texto é resultado do desenvolvimento do projeto de pesquisa intitulado Novos rumos para o Ensino de Sociologia nas escolas do Distrito Federal: qualificação e inovação pedagógica, realizado no quadro do EDITAL PRODOCÊNCIA 028/2010, da Coordenação de Aperfeiçoamento de Pessoal de Nível Superior (CAPES), que o financiou. Foi executado, coordenado e orientado pelo Decanato de Ensino de Graduação da UnB, 2011 a 2013 com participação de estudantes de Graduação em Ciências Sociais e de Pós-graduação em Sociologia da UnB.

${ }^{1}$ Universidade de Brasília (UnB) - Brasília (DF), Brasil. E-mail: sayonaraleal@uol.com.br DOI: 10.1590/ES0101-73302017151279
} 
which can be categorized in: institutionalized, disconnected andpropositional. We can conclude that both challenges and perspectives to the subject Sociology in the high school form of Brazilian Federal District involves, necessarily, the balance between the transmission of academic contents adapted to the social and cognitive profile of the students and the academic and teaching knowledge of the teachers whowork in diverse and adverse scholar contexts.

Keywords: Academic trajectory. Teaching knowledge and pedagogic mediations. TeachingofSociology. Schools in Federal District.

\section{DES SAVOIRS ENSEIGNANTS ET DES MÉDIATIONS PÉDAGOGIQUES POUR L'ENSEIGNEMENT DE SOCIOLOGIE AUX ÉCOLES: UNE ÉTUDE SUR LA FORMATION D'ENSEIGNANTS EN SCIENCES SOCIALES À L'UNIVERSITÉ DE BRASILIA}

RESUME: Cet article développe des aspects sociocognitifs et institutionnels liés au décalage de la formation pédagogique, des savoirs enseignants et des médiations pédagogiques en sciences sociales avec la pratique de l'enseignement des étudiants du premier cycle en sociologie et celle des enseignants des écoles publiques et privées au District Fédéral du Brésil. Basés sur des questionnaires, des entretiens semi-structurés et sur une analyse documentaire, nous proposons une typologie de représentations des pratiques d'enseignement en sciences sociales: institutionnalisées, déconnectées et propositionnelles. Nous en déduisons que les défis et les perspectives pour l'enseignement de la sociologie à l'école secondaire du District Fédéral portent sur l'adaptation des contenus pédagogiques et des savoirs enseignants à la diversité des profils sociocognitifs des élèves dans des contextes scolaires variés.

Mots-clés: Savoirs et formation d'enseignants. Médiations pédagogiques. Enseignement de sociologie. Écoles au District Fédéral.

\section{Introdução}

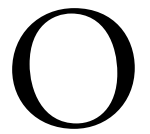

cenário institucional no qual o presente texto se insere está balizado pela problemática com a qual as políticas públicas de educação no Brasil têm se deparado, qual seja, o aperfeiçoamento e a melhoria do desempenho didático dos professores nos ensinos fundamental e médio no país ${ }^{1}$. Nosso objeto de investigação são os aspectos sociocognitivos e institucionais relacionados à questão do descompasso entre formação instrucional, saberes docentes e mediaçóes pedagógicas em Ciências Sociais expresso em práticas docentes de professores de Sociologia em escolas públicas e particulares do Distrito Federal, Brasil. Partimos de duas situações-problema fundamentais. A primeira está centra- 
da no debate sobre a missáo intelectual da disciplina, assim como sua legitimidade curricular e instrucional, para o ensino médio. Tal abordagem encontra importante eco em registros críticos de licenciandos em Ciências Sociais e professores de Sociologia do ensino médio sobre as condições sociais, estruturais e cognitivas com as quais essa disciplina é ministrada nas escolas. A segunda remete à discussão sobre os saberes docentes para o ensino de Sociologia no contexto escolar, os quais ultrapassam o conhecimento de teorias e métodos da disciplina e compreendem os recursos didáticos de transposição desse saber para o alunato do ensino médio, isto é, as chamadas mediaçôes pedagógicas (MORAN; MASETTO; BEHRENS, 2013). Tanto os aspectos epistemológicos da disciplina como os institucionais formam um complexo dispositivo de normatizaçáo do ensino de Sociologia na escola que informa saberes docentes e mediaçóes pedagógicas de licenciandos e professores de Ciências Sociais. Designamos aqui como dispositivos de normatização do ensino de Sociologia o arcabouço normativo e institucional que prevê, regulamenta e orienta conteudística e pedagogicamente o ensino de Sociologia enquanto disciplina partícipe da formaçáo instrucional de estudantes do ensino médio no Brasil. Tais dispositivos são formados por elementos heterogêneos dotados de certo grau de agenciamento, quais sejam: orientaçóes e parâmetros curriculares para regência das Ciências Sociais no espaço escolar, formaçáo instrucional na universidade, legislação que torna obrigatório o ensino de Sociologia nas escolas brasileiras, saberes docentes, mediaçóes pedagógicas normatizadas em função da Sociologia institucionalizada como ciência social.

Os saberes docentes em Ciências Sociais são vislumbrados, neste texto, a partir das características do preparo instrucional do licenciando na universidade e do professor de Sociologia em sala de aula em escolas, de acordo com os propósitos intelectuais, civilizatórios e cívicos atribuídos ao ensino de Ciências Sociais. O grande desafio que se impóe nesse ponto é justamente conciliar os mecanismos didáticos de mediação pedagógica de conhecimentos em Ciências Sociais e a formação de cidadãos mais esclarecidos sobre a realidade objetiva da qual fazem parte. Nesse sentido, o trabalho de Lahire (2007; 2004; 2013) acerca da utilidade intelectual do ensino de Sociologia no espaço escolar nos informa como essa disciplina cumpriria finalidades cognitivo-científicas, políticas e terapêuticas para o alunato/cidadão ${ }^{2}$, munindo-o de sentidos e categorias de percepção do mundo social.

No que concerne, especificamente, ao ensino das Ciências Sociais na escola, pode-se dizer que se espera do professor de Sociologia competência intelectual e didática para ministrar conteúdos - teorias clássicas e contemporâneas — em diálogo com as pretensōes republicanas e liberais imputadas à disciplina, que, no caso brasileiro, significa preparar para o vestibular e formar cidadãos. Trata-se de objetivos didático-pedagógicos que, muitas vezes, ultrapassam os saberes docentes apreendidos pelos licenciandos em sua fase de formação para se tornarem professores de Sociologia em escolas e não correspondem, em muitos casos, às críticas radicais feitas por esses universitários aos pilares institucionais e normativos das "sociologias" ministradas nas escolas. 
Nesse sentido, é nosso objetivo traçar repertórios de representações dos licenciandos em Ciências Sociais da Universidade de Brasília (UnB) acerca das práticas docentes de professores de Sociologia no ensino médio durante seus estágios supervisionados no espaço escolar. A confrontação com tais dispositivos pelos licenciandos de Ciências Sociais se dá em dois momentos fundamentais: durante a formação teórica na universidade e no momento da prática de ensino na escola. Nessas duas oportunidades podemos verificar que os discentes da licenciatura em Ciências Sociais entrevistados realizam um "trabalho normativo" importante ao se posicionarem criticamente diante de mecanismos institucionais e curriculares que definem sua formação docente e programam o exercício didático e pedagógico na mediação dos conteúdos de Ciências Sociais de professores observados em seus estágios docentes. As orientaçóes normativas que perpassam as práticas docentes em Sociologia na escola são alvo de críticas, desvios, rejeiçóes e reatualizaçóes pelos licenciandos, formando o que estamos nomeando aqui, nos termos de Dodier e Barbot (2014; 2015), de "repertório normativo"3, no qual estão elencadas algumas de suas representaçóes acerca da prática de ensino de Sociologia nas escolas. Com base nessas referências, organizamos uma tipologia mínima sobre as modalidades mais recorrentes em nossa investigação de representaçóes discentes de práticas docentes em Ciências Sociais observadas nas escolas, as quais podem ser classificadas em:

1. práticas docentes institucionalizadas;

2. práticas docentes desconexas; e

3. práticas docentes propositivas.

O primeiro tipo agrupa "imagens" expressas pelos licenciandos de uma Sociologia que vai à escola ancorada nos princípios normativos da institucionalização da disciplina no ensino médio, obedecendo aos dispositivos de ordenamento curricular e pedagógico que regem o conteúdo e o ensino das Ciências Sociais no espaço escolar sem problematizá-los, inclusive com foco excessivo nos exames seriados nacionais. O segundo tipo corresponde a deturpaçôes dos projetos político e pedagógico da Sociologia como parte da formação discente em nível médio e de seus conteúdos pelo professor, sendo o ensino das Ciências Sociais operado a partir da banalização e das distorçóes de conceitos e teorias e, até mesmo, da utilidade intelectual da disciplina, muitas vezes reforçando estigmas e preconceitos ou postulando formulaçóes ideológicas - como, por exemplo, a inabilidade do docente no tratamento de teorias críticas, como a marxista, ou de temas controversos como religiáo, aborto, racismo e gênero. $\mathrm{O}$ terceiro tipo se relaciona a práticas docentes propositivas que, embora estejam amparadas nos dispositivos institucionais e normativos que informam o ensino de Sociologia na escola, propóem uma integração mais promissora entre mediaçóes de conteúdos e estratégias didáticas para atrair/alcançar a atenção do alunato. As três si- 
tuaçóes decorrem das provas de realidade e existencial que o licenciando experimenta em sala de aula combinadas com sua expertise enquanto discente em Ciências Sociais, que o habilita a questionamentos da "verdade" proferida pelo docente como porta-voz da instituição Sociologia, resultando em críticas severas ao conteúdo e à sua mediação pedagógica em sala de aula. Essa classificação proposta nos permitiu acessar dimensões institucionais, normativas e cognitivas dos saberes docentes expressos nas práticas de ensino dos professores de Sociologia e na formação e experiência docente dos licenciandos de Ciências Sociais considerados nesta pesquisa.

Para operacionalizar a nossa coleta de dados, foram realizados os seguintes procedimentos: entrevistas semiestruturadas com professores de Sociologia que atuam nas escolas do Distrito Federal; aplicação de questionários a 34 licenciandos do curso de Ciências Sociais da UnB, em estágio de ensino supervisionado; e leitura e análise de 144 relatórios de estágio supervisionado produzidos por alunos da licenciatura, entre os anos de 2010 e 2014 . Os relatórios de estágio feitos por estudantes a partir da experiência da prática docente nas escolas constituem lugar epistêmico no qual são discutidos os conhecimentos construídos na interface entre universidade, escola e quadro normativo que regulamenta a Sociologia no ensino médio. Essa triangulação gera, por um lado, uma série de registros a respeito do desempenho pedagógico, didático e intelectual do professor observado no estágio docente pelo licenciando, nutrindo suas críticas sobre como a Sociologia é concebida e ministrada pelos docentes nas escolas, e, por outro, o leva a (re)pensar a sua própria formação para atuar como professor do ensino médio.

A respeito dos professores das escolas e dos licenciandos em Ciências Sociais entrevistados, procurou-se levantar as impressōes destes em relação ao exercício da prática docente no contexto escolar. Para os licenciandos, em específico, o foco foi o levantamento de seus perfis, dos instrumentos pedagógicos usados por eles para transmitir conteúdos programáticos em seus estágios supervisionados e de suas avaliaçóes tanto do quadro institucional e normativo que orienta o ensino de Sociologia nas escolas como da adequação de sua formação e seus conhecimentos para ministrar a disciplina para jovens e adultos do ensino médio. Ainda indagamos, nos dois casos, sobre os saberes docentes entendidos como necessários para a prática de ensino da disciplina em contextos diversos de aprendizagem inclusive na Educação para Jovens e Adultos (EJA).

Convém ressaltar que os dados da investigação sugerem que as práticas e os saberes docentes em Sociologia expressos na escola são alvos não apenas de operaçóes críticas por parte dos licenciandos em Ciências Sociais, mas também por parte do professor do ensino médio, o que aponta para manifestaçōes reflexivas acerca do ensino da disciplina nesse espaço em favor de movimentos de revisão e reversibilidade de mediaçôes pedagógicas estruturadas e rotinizadas.

Este texto está estruturado em duas partes, além desta introdução e das consideraçóes finais. Inicialmente, discutimos as implicaçōes da relação entre sa- 
beres e formação docentes para o ensino de Sociologia nas escolas. Logo após tratamos da formação instrucional de estudantes da Licenciatura em Ciências Sociais, considerando seus saberes docentes para lecionar essa disciplina no nível médio do período escolar. Em seguida evocamos as representaçóes das práticas docentes dos professores de Sociologia pelos licenciandos de Ciências Sociais. Nesse sentido, nos interessam as açóes e as situaçôes pedagógicas e didáticas reais no processo de ensino de conteúdos sociológicos para o alunato na escola com as quais aqueles licenciandos deparam e criticam a partir de um trabalho normativo revelador de suas competências para apontar adequaçóes e inadequaçóes nas práticas docentes observadas em sala de aula, conforme suas referencialidades de saberes docentes.

\section{Desafios curriculares e didáticos para o ensino das Ciências Sociais na escola: intersecção entre saberes e formação docentes}

Entende-se por saberes docentes um conjunto de conhecimentos manejados pelo professor, em duas dimensóes: cognitiva e social, ou seja, esses saberes devem orientar o docente na sua prática em contextos de ensino e aprendizagem de forma a permitir que ele lide tanto com conhecimentos acadêmicos quanto com conhecimentos interacionais, concernentes ao aspecto social da relação professor-alunato (BORGES, 2012).

Também nos parece importante pensar os saberes docentes a partir de uma abordagem curricular que contemple os conhecimentos ligados ao ensino e como estes repercutem na ação docente, e como os professores operam com esses saberes no contexto da sala de aula. O saber docente, nesse sentido, é também curricular, aquele que se refere ao conteúdo ministrado pelo professor em classe. Ao mesmo tempo, percebemos que os professores são produtores de conhecimentos e que existe um saber que emerge da prática profissional a partir da qual os docentes desenvolvem um conhecimento oriundo da atividade instrucional. Os saberes são moldados também pelas imprevisibilidades que ocorrem em tempo real em sala de aula, podendo oportunizar ao professor um contexto promissor para o desenvolvimento da capacidade de inovação e criatividade, permitindo, por exemplo, a adaptação do conteúdo ministrado à realidade do contexto social de ensino (BORGES, 2001). Isso porque a construção social dos saberes docentes extrapola a formação sistemática oferecida na universidade: o chamado "devir-formação" (COSTA; SOBREIRA, 2011, p. 77).

Nessa perspectiva, o estudo dos saberes docentes nos remete ao tema das inovaçóes em sala de aula porque essas rompem com velhas rotinas e se conectam com propostas de adequação de forma e conteúdo a situaçôes sociais específicas em que a escola, o professor e o alunato estão inseridos (CHRISTENSEN; HORN; JOHNSON, 2009). Nesses termos, a inovação em sala de aula traduz-se,cada vez mais, na postura propositiva do docente, adotando estratégias didáticas e pe- 
dagógicas que incluam o alunato na dinâmica da aprendizagem. Nesse sentido, o uso de tecnologias da informaçáo e da comunicaçáo (TICs) como instrumentos pedagógicos para preparaçáo e dinamização de aulas, inclusive na disciplina de Sociologia, como mostram apropriadamente Moran, Masetto, Behrens (2013), Silva (2013) e Beraldo e Barbato (2013), parece promissor. Náo se trata, portanto, de um processo revolucionário na educação, mas é algo que,em longo prazo, a partir do incremento de técnicas de ensino convencionais, pode provocar mudanças estruturais no modo de ensino em sala de aula e, sobretudo, na relação social entre professor, ensino (Sociologia) e alunato.

\section{Algumas reflexões sobre o ensino de Sociologia nas escolas brasileiras}

Mesmo diante do reconhecimento da "essencialidade" intelectual e pedagógica das Ciências Sociais como disciplina escolar, o ensino de Sociologia nas escolas brasileiras enfrenta três dificuldades gerais. A primeira delas se dá muito em função das conturbaçóes de sua legitimação curricular no ensino básico e diz respeito a cobranças cognitivas acerca da formação e do desempenho do licenciando em Ciências Sociais. Trata-se do que estamos nomeando aqui de "racismo instrucional-intelectual" em Ciências Sociais, muito próximo da concepçáo bourdiesiana de "racismo de inteligência" (BOURDIEU, 1980), porque diz respeito à estratégia de distinção por um grupo que se diferencia intelectualmente por suas qualidades epistêmicas pretensamente superiores devido à detenção de um tipo de capital cultural, fruto de um preparo instrucional diferenciado, em princípio, mais relevante para um desempenho cognitivo mais adequado a um cientista social, capacitando-o para a investigação científica. Essa modalidade de racismo que se estabelece no seio dos cursos de Ciências Sociais é característica do ambiente institucional de uma habilitação instrucional cujo poder se baseia, em parte, na posse de um diploma de bacharel que remete a uma garantia de expertise superior em comparação àquela adquirida na licenciatura. Trata-se de uma forma eufemizada de racismo apoiado no discurso técnico de déficits conteudísticos da formação do licenciando em Ciências Sociais (Sociologia) em relação aos bacharéis. Assim, temos deficiências curriculares que podem se converter em deficiências instrucionais-intelectuais. Isso conduz à subvalorização das disciplinas específicas da licenciatura em relação à sobrevalorização das disciplinas e formação do bacharelado em Ciências Sociais, levando a uma falsa dicotomia entre ensino e pesquisa na formação de docentes de Sociologia. Ou seja, o alunato do bacharelado seria mais dotado e treinado para a pesquisa do que aquele que opta pela licenciatura. Portanto, o primeiro estaria intelectualmente mais apto para o exercício do ofício de cientista social do que o segundo.

O pressuposto de um desvelamento cognitivo/intelectual entre os formandos do bacharelado e os da licenciatura ainda na universidade, como apontam alguns autores como Oliveira (2011), Handfas (2009) e Handfas e Maçaira 
(2012), gera uma desarticulação temerosa entre pesquisador (bacharel) e professor (licenciado), que desemboca no espaço escolar. Faz-se necessária, assim, como bem destaca Oliveira (2011), a articulação entre ensino e pesquisa na formação do licenciando em Ciências Sociais a partir da problematização da própria natureza do conhecimento sociológico, que, em última instância, atrela-se à legitimidade da disciplina no currículo escolar. Além disso, um modelo formativo em Ciências Sociais no ensino superior que opere a separação em sua grade curricular entre bacharelado e licenciatura também pode reforçar a hierarquização entre os dois cursos. (HANDFAS, 2009; SOUSA; REGHIM; GOMES, 2012).

Uma segunda dificuldade, mais de fundo institucional, diz respeito às barreiras para a constituição dos saberes docentes em Ciências Sociais, como postulam Oliveira e Sobreira (2011), as quais resultam da distância entre as políticas educacionais de Estado e a sua implementação propriamente dita no campo da decisão de cada professor sobre exercitá-las ou náo. Entra em perspectiva, aqui, a decisão do professor de Ciências Sociais de trabalhar determinados conteúdos considerados polêmicos — como raça, gênero e religião — em detrimento de outros, a partir de recursos didáticos também à sua escolha, estabelecendo-se, assim, uma ponte entre a sua formação sistemática universitária e suas orientaçóes curriculares e a sua prática em contextos escolares específicos nos quais está inserido para compreendermos seus saberes docentes.

As Orientaçôes Curriculares Nacionais - Ensino Médio (OCNEM) publicadas em 2006 dão alguns direcionamentos para a condução dos conhecimentos docentes em Ciências Sociais. Nesse documento, o ensino de como fazer investigação dirigido aos alunos do nível médio aparece como um elemento relevante, na metodologia de ensino de Sociologia, para o conhecimento da pesquisa sociológica e de seus procedimentos de objetividade científica e ainda como instrumento de prática escolar, com orientaçóes sobre as pesquisas bibliográficas e seus diversos tipos de fontes.

Outro documento importante para pensarmos o conteúdo da disciplina de Sociologia para o nível médio é a nova Lei de Diretrizes e Bases (LDB), que traz quatro objetivos do ensino médio: prosseguimento de estudos, preparação para o trabalho, aprimoramento da pessoa humana — formação ética, autonomia intelectual e pensamento crítico — e compreensão dos fundamentos científicotecnológicos dos processos produtivos — teoria e prática (BRASIL, 1999; 2002; 2006). Ao elencar esses propósitos, em geral, para o ensino médio, pode-se pensar o curso de Sociologia como lócus privilegiado para o cumprimento de tais objetivos dentro da grade conteudística da disciplina. (MORAES, 2009; HANDFAS, 2009; OLIVEIRA, 2011).

No que tange à disciplina de Sociologia, a perspectiva é que se dialogue com os propósitos atribuídos a ela por recomendação dos elaboradores das Orientações Curriculares Nacionais (OCNs), tais como a formação para a cidadania, 
o estranhamento e a desnaturalização, contemplando a discussão das relações e estruturas sociais, das diferentes formas de organização social e das situaçôes de vida em sociedade.

Uma terceira dificuldade reside no fato de que as Ciências Sociais vêm sendo ministradas nas escolas do país, muitas vezes, sem que o professor detenha os saberes fundamentais para conduzir esse conteúdo por não ter formação na área. Além disso, em alguns casos, as escolas não priorizam esse conteúdo para o preparo do alunato para o vestibular. Conforme Baltar (2015), em 2012 tínhamos no país 54.654 professores ministrando turmas de Sociologia no ensino básico, dos quais 49.041 (89,7\%) não tinham formação em Ciências Sociais e 10,3\% tinham formação na área. $\mathrm{O}$ autor destaca, entretanto, que o número de docentes de Sociologia nas escolas mais do que dobrou entre 2008 e 2012, embora a participação dos licenciados em Ciências Sociais/Sociologia nesses postos de trabalho tenha diminuído $1,7 \%$.

Diante das polêmicas e do problema do ensino de Sociologia nas escolas brasileiras - em específico no Distrito Federal, que desde 1999 adotou a disciplina nos currículos das escolas públicas - , preocupamo-nos em discutir a adequação da formação instrucional ofertada pela Licenciatura em Ciências Sociais da UnB às necessidades de aprendizado dos licenciandos, no sentido de preparo conteudístico e didático para atuarem em diferentes contextos de ensino de Sociologia em escolas públicas e particulares.

\section{Formação docente em Ciências Sociais: o caso dos licenciandos da UnB}

O curso de Licenciatura em Ciências Sociais da UnB surgiu em 1968 e, desde então, adota um modelo curricular que integra, ao mesmo tempo, bacharelado e licenciatura, levando o alunato a complementar sua formação com disciplinas específicas em outras unidades acadêmicas da universidade, como as faculdades de educação e de psicologia, ficando a cargo do Instituto de Ciências Sociais a disciplina de Prática de Ensino em Ciências Sociais. Trata-se do primeiro e único curso de formação docente em Ciências Sociais do Distrito Federal. Disso decorre, em grande parte, a preocupação que se nutre em relaçáo aos saberes docentes apropriados e desenvolvidos pelos professores de Sociologia que atuam nas escolas do Distrito Federal.

Dos 34 alunos entrevistados em nossa pesquisa que cursaram a Licenciatura em Ciências Sociais da UnB entre 2010 e 2014 — os quais chamaremos de L - apenas 2 fizeram somente a opção pela licenciatura; os demais optaram prioritariamente pelos bacharelados em Sociologia e Antropologia. Porém, 17 deles admitem que a licenciatura é hoje prioritária. Entre os principais estímulos 
para cursar a habilitação em Licenciatura em Ciências Sociais apontados pelos entrevistados temos: a insatisfação com o ensino de Sociologia nas escolas quando foram alunos do ensino médio e estagiários docentes; a importância da Sociologia no ensino básico para ampliar a percepção das pessoas acerca da realidade e para o aprofundamento do papel do ator social; as maiores chances de inserçáo no mercado de trabalho; e a união da docência com a pesquisa. Alguns entrevistados exprimem as seguintes sentenças: "Além de acreditar na educação como mecanismo transformador, a não garantia de emprego em outras áreas e as condiçóes de trabalho insuficientes que estão destinados aos jovens, a licenciatura se torna mais uma garantia de emprego" (L13); "Tenho muita vontade de ser professora de Sociologia no ensino médio. Eu realmente tenho paixão pela área. Não somente pretendo atuar na área de educação, mas pretendo também pesquisar na área” (L14).

Essas respostas nos levam a vislumbrar o papel instrutivo da Sociologia nas escolas atribuído por aqueles que realizaram a prática de ensino. Em geral, os respondentes da pesquisa conferem à disciplina de Sociologia no ensino médio atributos tanto cognitivo-científicos como políticos. Em relação ao primeiro, vislumbra-se uma função esclarecedora acerca da "realidade" vigente e das condições e dos elementos sociais que a constituem, quase no sentido iluminista de formar cidadãos esclarecidos e, portanto, críticos, capazes de expressar suas consideraçóes sobre a dita "realidade". Já em relação à finalidade política, a disciplina cumpriria o papel de formação para atuação na vida pública, em termos de uma "consciência" de diagnósticos do mundo social. A esse respeito, alguns licenciandos exprimem: "A sociologia servirá de alicerce para o desenvolvimento do senso crítico embasado em discussóes contemporâneas, sempre mantendo o caráter científico" (L1); "Acredito que o ensino de Sociologia estimule o livre pensamento, a crítica e uma percepção do meio social que de outra forma pouco se estabelece na vida do aluno, que passa pela escola 'anestesiado"” (L3); "A Sociologia pode ser um instrumento de conscientização, mas isso depende, obviamente, dos recursos, da prática e da forma como ela é conduzida" (L8); "A Sociologia contribui para a constituição de um pensamento crítico; ela exercita formas de pensar e interpretar o mundo" (L11); "Perceber como são os processos sociais, comportamentais e políticos do Brasil e do mundo é essencial para o cidadão e para o ser humano. A Sociologia deveria mostrar tais processos" (L18).

Se bem direcionada, pensando em sociologia, antropologia e ciência política, o aluno sairia com uma capacidade de analisar criticamente a sua própria realidade, tendo autonomia de pensamento sobre o que ele mesmo vive, com menos viés possível, se sentindo capaz de fazer escolhas de pensamento autônomas. (L20)

A percepção do lugar da Sociologia no currículo do ensino médio para os licenciandos da UnB nos leva a considerar a experiência de lecionar a matéria nas escolas, segundo esses futuros docentes, a partir de três registros, nos termos 
também observados por Santos (2002). Primeiro, a disciplina deve permitir ao alunato das escolas o domínio de conceitos, teorias e métodos das Ciências Sociais - função cognitiva. Segundo, deve habilitar esses estudantes para a intervenção instruída, a partir de uma atitude política, em processos da vida social, desde situaçóes ordinárias do dia a dia até cenários, por exemplo, de eleiçóes, permitindo, em terceiro lugar, que esses indivíduos compreendam sua participação como atores e náo expectadores de interaçóes sociais nas e pelas quais constroem e reproduzem suas referências de pensamento e ação - função terapêutica.

Esses registros sobre a utilidade da Sociologia no ensino médio, somados aos saberes docentes dos estudantes e a suas experiências de estágios nas escolas, formam a base para suas críticas em relação a suas próprias práticas de ensino como parte da sua formação instrucional. Para esses licenciandos, a "prova" da prática docente em sua formação é insuficiente para prepará-los para a atuação como professores de Sociologia no contexto escolar devido, sobretudo, à escassez de oportunidades de, efetivamente, ministrarem aulas no ensino médio, seja porque a escola ou o professor da disciplina não permitem. Nesse sentido, a prática de ensino (PE) figuraria mais como experiência etnográfica do que como preparo docente informado pela regência em sala de aula propriamente dita. Assim, para esses futuros profissionais do magistério, nem o estágio docente nem as disciplinas obrigatórias da Licenciatura em Ciências Sociais da UnB foram suficientes para prepará-los para a atuaçâo docente nas escolas. Segundo os licenciandos: "Foi boa e interessante [a experiência docente], mas a falta de continuidade tornou a experiência um tanto quanto estérea. Lecionei apenas uma aula" (L3); "A experiência mostrou as dificuldades que um professor pode enfrentar em uma sala de aula da periferia, mas contribuiu para me aproximar do fascínio que a educação pode exercer" (L4); "Acho que o estágio serve mais para a pesquisa, no caso de como anda a disciplina na rede de ensino, mas pouco se aprende como é estar em sala de aula, dar aula" (L9).

O segundo aspecto importante apontado pelos licenciandos é a essencialidade da formação em Ciências Sociais para o exercício do magistério na disciplina de Sociologia nas escolas. Nos depoimentos registrados nos relatórios de estágio e nos questionários respondidos pelos licenciandos, cerca de $50 \%$ dos professores observados nas escolas do Distrito Federal têm outras formações, tais como: Geografia, História, Estudos Sociais e Administração. De acordo com um professor (P) de Sociologia, graduado em Administração, que ministra a matéria há 10 anos na rede pública do Distrito Federal:

A minha formação acadêmica foi bacharel em Administração de Empresa e também licenciatura plena. E, como é licenciatura, eu fiz o curso de extensão de Sociologia, que complementa a graduação [...] se bem que, pelo meu currículo, dava pra eu dar aulas de várias matérias, sabe. Mas eu fiz mesmo de propósito curso de extensão (P1). 
Outra professora de Sociologia entrevistada, formada em Filosofia e História, que leciona na rede particular do Distrito Federal, expóe:

Quando eu vim pra Brasília eu lecionava História, Educação Física e Filosofia no Carmen Salles. Aí depois eu acabei encolhendo, porque eu trabalhava de noite [...] aí eu encolhi e fiquei só na Filosofia e História [...] Porque lá no Imaculada mesmo eu dei Sociologia, depois me tiraram de Sociologia e me botaram em História, me botaram de volta pra Sociologia... (P2).

Já para outros professores entrevistados, a disciplina de Sociologia não poderia ser ministrada por docentes formados em outras áreas, mesmo naquelas afins às Ciências Sociais:

Sou adepto dessa postura [formação em Ciências Sociais obrigatória para ministrar Sociologia no ensino médio] com unhas e dentes, né. É a grande questão [???]... tem professores que dão aula de Ética e não são formados em Filosofia, às vezes são formados em Direito ou em Administração. E eu defendo que o professor que dá Ética tem que ser formado em Filosofia, assim como o professor que dá aula de Sociologia tem que ser formado na área (P3).

Da parte dos licenciandos, a formação dos saberes docentes em Ciências Sociais se torna um importante alvo de reflexão sobre a qualidade do ensino de Sociologia ministrado nas escolas do Distrito Federal quando confrontada coma grade de disciplinas específicas da Licenciatura em Ciências Sociais do Departamento de Sociologia da UnB. Isso acontece, sobretudo, porque esses estudantes problematizam seu preparo instrucional e o conteúdo dessas matérias em termos de adequação às bases curriculares e aos contextos escolares locais de prática docente. Na avaliação de alguns: "Especificamente, nas matérias oferecidas pelo Departamento de Sociologia, o conteúdo foi bem bom, mas as matérias do Departamento de Pedagogia foram fracas, generalistas e desinteressantes, em sua maioria” (L3); "Deveria haver uma articulação entre as matérias da Pedagogia, por exemplo, e as matérias, conteúdos que serão ministrados em sala de aula, como também um maior preparo dos alunos para a prática de ensino de Sociologia" (L5); "Há muito poucas matérias que preparam para a licenciatura. Estou em meu penúltimo semestre e nunca havia pensado em inúmeras questóes básicas ao ensino de Sociologia nas escolas" (L3); "Não há disciplinas voltadas para a Sociologia, e a grade ofertada pela Faculdade de Educação está defasada, inclusive com matérias que repetem o conteúdo sem trazer discussóes contemporâneas” (L19).

Há outro problema observado e declarado pelos entrevistados sobre a formação docente: a falta de interação entre as diferentes esferas que formam a arquitetura institucional para o ensino de Sociologia nas escolas do Distrito Federal. Há, de fato, pouca aproximação entre o Departamento de Sociologia, a Univer- 
sidade e a Secretaria de Educação do Governo do Distrito Federal (GDF) e as escolas públicas e privadas da região. Essa pode ser aqui considerada uma das causas da dificuldade que os estagiários enfrentam para iniciar e realizar plenamente seus estágios nas escolas.

No geral, os licenciandos sugerem algumas iniciativas para a melhora do curso, tais como: mais acesso,durante o curso,a informaçóes sobre atualidades da carreira docente; mais disciplinas específicas em Ciências Sociais ofertadas durante a habilitação pelo Departamento de Sociologia; mais prática de ensino e orientaçóes para planejamento de aulas; oportunidades de lecionarem de fato durante a prática de ensino como quesito obrigatório para a realização do estágio; contrataçấo de professores para a licenciatura; estágio em duas etapas - observação e participação; relacionar mais a disciplina com o cotidiano do aluno; e mais seriedade na condução das disciplinas obrigatórias da licenciatura.

Os futuros docentes recomendam também: "maior aprofundamento teórico a respeito do sistema escolar e das formas de educação não formais" (L10); e "ampliar a oferta de disciplinas voltadas para a educação, estimular o departamento a investigar cientificamente a educação, estimular a redação de uma proposta curricular para o ensino médio" (L21). As falas dos discentes da licenciatura enfatizam também o problema do desprestígio dessa habilitação, evocando a subvalorizaçáo da licenciatura no quadro geral do curso de Ciências Sociais na UnB. Um dos estudantes sugere:

Oferecer mais disciplinas que façam com que a licenciatura permeie toda a graduação e seja uma preocupação constante ao invés de aparecer desvalorizada, mais para o final do curso e, muitas vezes, como alternativa de emergência e que os graduandos tenham mais oportunidades de prática e concepção de planejamento de aulas. (L13)

Em relação às condiçóes estruturais de trabalho, diferentemente do relatado no caso das escolas particulares, os professores das escolas públicas não dispunham de equipamentos tecnológicos de última geração - como lousa digital, retroprojetor e laboratórios. Os materiais mais utilizados pelos professores das escolas públicas são livros didáticos, apostilas elaboradas pelos próprios professores e textos. Registros a respeito da utilização de equipamentos de vídeo e retroprojetores raramente apareceram nos diários de campo dos licenciandos, mas, quando há introdução dessas e outras tecnologias como ferramentas para ministrar conteúdo sociológico ou realizar diagnósticos acerca do mundo social - uso de artefatos técnicos para filmagem e fotografia de cenas do cotidiano - , há um ganho em termos de motivação e aprendizado por parte do alunatón .

As críticas e formulaçóes sugestivas desses licenciandos remetem ao tratamento didático-pedagógico e curricular da questão da articulação entre pesquisa 
e ensino na formação do docente em Ciências Sociais, como tratado por Oliveira (2011), para o enfrentamento das fragilidades de seus saberes docentes em sua dimensão instrucional e institucional. Nesse sentido, é importante enfatizar que o estágio docente precisa ser pensado como rito de passagem entre a licenciatura e a docência de fato. (HANDFAS; TEIXEIRA, 2007). Assim, destacamos a relevância das representaçóes que os licenciandos exprimem acerca do ensino de Sociologia ministrado pelo professor da disciplina na escola, observando seus saberes e suas mediações pedagógicas, porque esses são insumos importantes para sua (re) construção enquanto profissionais do magistério.

\section{Conexões entre dispositivos de normatização do ensino de Ciências Sociais, saberes e práticas docentes de Sociologia em escolas do Distrito Federal}

O trabalho normativo operado pelos licenciandos em relação aos elementos que compóem os dispositivos de ordenamento do ensino de Sociologia nas escolas do Distrito Federal parte dos modos de constituição de uma "ordem social" e diz respeito à maneira pela qual esses e os professores de Ciências Sociais podem pensar suas próprias situaçóes e os quadros de pensamentos e conhecimentos desenvolvidos no seio das instituiçóes em que discentes e docentes se inserem. Nesse sentido, para tratar de questôes como a adequação de saberes e práticas para ensinar Ciências Sociais ao público do espaço escolar, é preciso mergulhar no pensamento institucional que os indivíduos têm em mente no momento em que agem, compreendendo categorias de pensamentos que compartilham, referenciadas em um determinado quadro de ordem social. (DOUGLAS, 1998). É nesse sentido que dispositivos de normatização do ensino de Sociologia são mecanismos de ordenamento que conduzem a forma como licenciandos e docentes podem conceber a disciplina e agir, contribuindo, assim, para a estabilidade da disciplina de Sociologia no ensino médio enquanto uma instituição social,que corresponde ao que foi estabelecido no quadro normativo que rege a sua definição e a sua existência na grade curricular da escola.

O ordenamento da Sociologia como disciplina do ensino médio, conforme as orientaçóes da Licenciatura em Ciências Sociais da UnB e os parâmetros e as orientaçóes curriculares nacionais e distritais, se traduz em certo instrumento de autoridade no regimento de práticas docentes, com respaldo de bases institucionais. Porém, valores, normas e orientaçóes incorporados aos dispositivos de ordenamento da Sociologia na escola são também subsídios para aquilo que Boltanski (2008) chama de "contradiçóes hermenêuticas" no quadro de operaçóes críticas acerca de normas informadas pelo caráter estruturante de uma instituição. A noção de contradiçóes hermenêuticas aparece como reveladora do processo de dominação no seio dos mecanismos de produção de saberes, no sentido de restri- 
ção do espaço da crítica diante de enquadramentos normatizadores em contextos nos quais a realidade forjada pela força da racionalidade tecnocientífica e da institucionalização de comportamentos e açóes se sobrepóe ao mundo das possibilidades de agir, inclusive em situaçóes de ensino.

$\mathrm{O}$ advento de novos cenários de prática de ensino de Sociologia nas escolas do Distrito Federal decorre de rompimentos e adequaçóes de dispositivos que normatizam tanto a formação do docente em Ciências Sociais como a disciplina em seus conteúdos e seu ensino. As práticas de ensino em Ciências Sociais, nesse sentido, enquanto lócus de manifestação de saberes docentes, mediações pedagógicas e de construção de conhecimento, podem oscilar entre registros distintos de validade, veracidade e provas, segundo as representaçóes de seus observadores, licenciandos em estágio supervisionado ${ }^{5}$. Esses são submetidos a modalidades de provaçóes da prática docente nas quais efetivamente se deparam com conformidades, deturpaçóes e reformulaçóes dos ordenamentos curriculares que instruem saberes e mediaçóes colocados em prática pelo professor de Sociologia. Nesses termos, o trabalho normativo dos licenciandos compóe um importante repertório de representações de práticas de ensino de Sociologia nas escolas que problematizam a disciplina desde seus propósitos instrucionais e intelectuais até sua mediação no espaço escolar pelo professor, contrariando, concordando, desprezando orientaçóes curriculares que compóem os mecanismos de sua institucionalizaçáo no espaço escolar.

Os saberes docentes experimentados pelos licenciandos se encontram objetivados nas práticas de ensino de Sociologia de forma tanto reificada como reinventada, sinalizando experiências didáticas e pedagógicas que oscilam entre práticas estruturadas e práticas reflexivas. Disso decorre, em grande parte, a constatação em nossa investigação de três tipos mais recorrentes de representações de práticas docentes do ensino de Sociologia pelos licenciandos em seus estágios na escola: institucionalizadas, desconexas e propositivas. Essa tipologia é inspirada na leitura dos relatórios de estágios docentes dos licenciandos em Ciências Sociais da UnB e também encontra-se amparada em entrevistas fechadas - com questionários — realizadas com estudantes da licenciatura. Foi adotado o procedimento de análise de conteúdo desse material, com codificação temática, nos termos de Bardin (1977), seguindo também a perspectiva moscoviciana de valorização dos atos de palavra oral e escrita, levando em consideração as condições de produção do texto - experiência da PE na formação do licenciando. Partimos do pressuposto de que agenciamentos operados pelos saberes docentes em Ciências Sociais, em suas dimensões institucionais e normativas, assim como as críticas dirigidas a esses dispositivos pelos licenciandos, orientam suas crenças, seus conceitos e suas representaçóes sociais a respeito da Sociologia e do seu ensino na escola, elaboradas e transmitidas via mensagens, discursos e enunciados. (FRANCO, 2005). $\mathrm{Na}$ Tabela 1, apresentamos situaçóes de PEs de Sociologia citadas por licenciandos a partir de seus estágios docentes nas escolas do Distrito Federal. 
O primeiro tipo representa $60,42 \%$ da nossa amostra e diz respeito a práticas de ensino mais ancoradas nas orientaçóes e nos parâmetros curriculares, inclusive com a adoção de livros didáticos indicados pelo Programa Nacional do

\section{Tabela 1}

Distribuiçãodas falas dos licenciandos que remetem à classificação de práticas de ensino de Sociologia observadas nas escolas durante as aulas de Ciências Sociais (base: 144 relatórios de estágio docente).

\begin{tabular}{|c|c|c|}
\hline $\begin{array}{l}\text { Algumas situaçóes de prática de ensino mencionadas nos relatórios dos } \\
\text { estágios docentes }\end{array}$ & n. & $\%$ \\
\hline \multicolumn{3}{|l|}{ Situaçôes relacionadas à PE institucionalizada } \\
\hline $\begin{array}{l}\text { Aulas expositivas, muitas vezes consideradas monótonas, cujo conteúdo } \\
\text { abordado segue a cronologia do livro didático, assim como os exercícios. }\end{array}$ & \multirow{6}{*}{87} & \multirow{6}{*}{60,42} \\
\hline $\begin{array}{l}\text { Aulas quase que estritamente orientadas pelos conteúdos que interessam aos } \\
\text { exames nacionais seriados - PAS, ENEM- e ao vestibular. }\end{array}$ & & \\
\hline $\begin{array}{l}\text { Professor "refém" do livro didático, sem propor nada além desse } \\
\text { instrumento para dar aulas. }\end{array}$ & & \\
\hline $\begin{array}{l}\text { Professor que segue literalmente o material didático determinado pela } \\
\text { escola (particular). }\end{array}$ & & \\
\hline $\begin{array}{l}\text { Visáo restrita do professor em relaçáo ao entendimento da Sociologia como } \\
\text { disciplina de caráter puramente civilizatório, não permitindo romper com o } \\
\text { senso comum. }\end{array}$ & & \\
\hline $\begin{array}{l}\text { Aulas consideradas corretas, do ponto de vista dos conteúdos e das } \\
\text { mediaçóes pedagógicas, mas não táo instigantes. }\end{array}$ & & \\
\hline \multicolumn{3}{|l|}{ Situaçóes relacionadas à PE desconexa } \\
\hline $\begin{array}{l}\text { Aulas ministradas com base no livro didático, cujos temas são sugeridos } \\
\text { pelas orientaçốes curriculares, mas com muitas incidências de equívocos } \\
\text { conceituais, erros de português e desconhecimento de conceitos básicos das } \\
\text { Ciências Sociais. }\end{array}$ & \multirow{7}{*}{37} & \multirow{7}{*}{25,69} \\
\hline $\begin{array}{l}\text { Incapacidade dos docentes de lidar com conteúdos que integram as } \\
\text { orientaçôes curriculares para Ciências Sociais no ensino médio. }\end{array}$ & & \\
\hline $\begin{array}{l}\text { Exposição de conteúdos de outras disciplinas das Ciências Humanas - } \\
\text { Filosofia, História — sem estabelecer conexão com a utilidade pedagógica } \\
\text { dessas para tratar de conteúdos das Ciências Sociais. }\end{array}$ & & \\
\hline $\begin{array}{l}\text { Aulas que náo remetem aos conteúdos e às abordagens das Ciências Sociais, } \\
\text { levando o alunato a confundi-las com as demais áreas de conhecimento, } \\
\text { como Jornalismo, Filosofia e História. }\end{array}$ & & \\
\hline Desconhecimento das orientaçôes curriculares nacionais e distritais. & & \\
\hline $\begin{array}{l}\text { O professor não tem propriedade para abordar os clássicos Durkheim, } \\
\text { Weber e Marx, chegando até a confundir conceitos básicos. }\end{array}$ & & \\
\hline $\begin{array}{l}\text { Abuso de recursos audiovisuais como forma de mediação pedagógica, sem } \\
\text { aulas expositivas preparatórias das discussóes. }\end{array}$ & & \\
\hline
\end{tabular}




\section{Tabela 1}

Continuação.

\begin{tabular}{|c|c|c|}
\hline $\begin{array}{l}\text { Algumas situaçóes de prática de ensino mencionadas nos relatórios dos } \\
\text { estágios docentes }\end{array}$ & n. & $\%$ \\
\hline Aulas ministradas sem recorrer a qualquer material didático. & \multirow{4}{*}{37} & \multirow{4}{*}{25,69} \\
\hline $\begin{array}{l}\text { O docente expõe a opinião dele, "contaminando" o conteúdo, e subestima } \\
\text { a capacidade dos alunos de conversarem criticamente sobre os temas atuais } \\
\text { da sociedade. }\end{array}$ & & \\
\hline $\begin{array}{l}\text { Para o docente observadonão valia a pena realizar uma boa aula porque os } \\
\text { alunos não queriam aprender e esse esforço não tinha retorno. }\end{array}$ & & \\
\hline $\begin{array}{l}\text { Uso político da disciplina de Sociologia e a sua não existência no ensino } \\
\text { médio, uma vez que é lecionada de forma "genérica". }\end{array}$ & & \\
\hline \multicolumn{3}{|l|}{ Situações relacionadas à PE propositiva } \\
\hline $\begin{array}{l}\text { Uso de recursos audiovisuais - filmes, documentários, música — e poesia } \\
\text { para tratar, com conceitos, o objeto da aula de Sociologia (Exemplo: } \\
\text { discussão sobre direitos humanos a partir da exibiçáo do filme "A } \\
\text { cor púrpura"). }\end{array}$ & \multirow{10}{*}{20} & \multirow{10}{*}{13,89} \\
\hline $\begin{array}{l}\text { O professor faz uso do raciocínio histórico para incentivar a "imaginação } \\
\text { sociológica" do alunato, mas enfatizando abordagens e conceitos das } \\
\text { Ciências Sociais. }\end{array}$ & & \\
\hline $\begin{array}{l}\text { Estímulo do professor à produção de etnografias pelos alunos a partir } \\
\text { dos seus contextos sociais, no cotidiano, para aguçar sua "imaginação } \\
\text { sociológica" ao levá-los a tratar de conceitos das Ciências Sociais a partir de } \\
\text { seus relatos. }\end{array}$ & & \\
\hline $\begin{array}{l}\text { Professor adota postura autônoma em relação aos OCNs e PCNs devido às } \\
\text { especificidades da localidade em que dá aula. }\end{array}$ & & \\
\hline $\begin{array}{l}\text { Utilização pelo professor de blogsobre a disciplina e "TwitAula" para } \\
\text { complementar o ensino de Sociologia. }\end{array}$ & & \\
\hline $\begin{array}{l}\text { O professor elabora uma apostila que aborda os conceitos a serem } \\
\text { trabalhados ao longo de cada bimestre. O material fica disponível para } \\
\text { download no blog. }\end{array}$ & & \\
\hline $\begin{array}{l}\text { O professor recorre a obras literárias, escolhendo um livro que deve ser } \\
\text { lido até o final do semestre. Propóe o desenvolvimento da "imaginação } \\
\text { sociológica" e incentiva a leitura. }\end{array}$ & & \\
\hline $\begin{array}{l}\text { No contexto da EJA, o papel do professor, devido às contingências, é ser } \\
\text { mais do que um educador; é ser um agente da transformaçâo social no nível } \\
\text { da micropolítica. }\end{array}$ & & \\
\hline $\begin{array}{l}\text { Cineclube organizado pelo professor é uma iniciativa bem-sucedida de } \\
\text { atrair os alunos para práticas extraclasse voltadas à análise crítica de assuntos } \\
\text { propostos por ele a partir de filmes. }\end{array}$ & & \\
\hline $\begin{array}{l}\text { As aulas são ministradas de forma criativa para que os alunos interajam com } \\
\text { o conteúdo; por isso a utilizaçáo de recursos midiáticos e audiovisuais. }\end{array}$ & & \\
\hline
\end{tabular}

Fonte: Elaboração a partir da pesquisa realizada.

PE: prática de ensino; PAS: Programa de Avaliação Seriada; ENEM: Exame Nacional do Ensino Médio; OCNs: orientaçōes curriculares nacionais; PCNs: parâmetros curriculares nacionais; EJA: Educação de Jovens e Adultos. 
Livro (PNL) como principal material informativo da disciplina. Essa modalidade de prática docente está amparada em instâncias de confirmação da coerência entre formas simbólicas e estado de coisas dada pelas normas da instituição — ensino de Sociologia ou da escola —, não havendo adesão importante a estratégias didáticas e pedagógicas inovadoras nem a conteúdos para além daqueles recomendados pelas orientaçóes curriculares e pela própria direção da escola - no caso das escolas particulares. Nesse sentido, ao ministrar seu curso, o professor segue as normas, reduzindo incertezas sobre conteúdos e formas, alinhando-se a um enquadramento da ação, conforme orientaçôes curriculares e institucionais.

O segundo tipo de representaçóes de PE corresponde a 25,69\% de nossa amostragem e se refere a práticas apartadas do quadro normativo — orientações e parâmetros curriculares, livro didático, saberes docentes institucionalizados que apresentam distorções em relação às teorias e aos métodos das Ciências Sociais. Nessa situação, enfatiza-se o desconforto de alguns docentes na condução da disciplina junto ao alunato do ensino médio e o seu déficit de preparo instrucional para lidar com temáticas mais controversas, como religião, gênero, raça, estratificação social e ideologias políticas. As práticas desconexas despertam nos discentes da Licenciatura em Ciências Sociais tanto sentimentos morais de revolta, indignação e desencanto com a profissão, sendo o docente considerado como antimodelo de professor de Sociologia, quanto uma oportunidade de redefinição e confirmação de suas convicçóes acerca da disciplina de Ciências Sociais na escola e do magistério.

O tipo PE propositiva equivale a $13,89 \%$ de nossos dados e se refere à atitude do docente observado no estágio supervisionado. Esse gênero de prática se apoia na realidade do contexto de ensino de Sociologia na escola a partir da qual se erigem críticas subsidiadas em saberes docentes do professor, os quais decorrem da sua perspectiva político-pedagógica sobre a utilidade das Ciências Sociais na formação de seus alunos. Disso decorre que, mesmo fundamentadas nos dispositivos de normatização da disciplina de Sociologia, sobretudo os conteúdos e as metodologias de ensino mais institucionalizados, as práticas docentes apresentam incrementos tanto nas mediações pedagógicas de teorias e métodos quanto na escolha de conteúdos didáticos em Ciências Sociais dirigidas ao alunato. De um lado, têm-se jogos, teatro, atividades de pesquisa de campo, uso de tecnologias da informação e redes sociais na internet para ensinar Sociologia, e, do outro, assistese ao tratamento de temáticas polêmicas como aborto, feminismo, a condição do negro na sociedade brasileira, ideologias partidárias e questóes públicas referentes ao contexto social e geoespacial no qual o alunato está inserido - o contexto específico das regióes administrativas do Distrito Federal, por exemplo. A condução das aulas se apoia em material didático também pesquisado pelo docente, sobretudo em pesquisas recentes que abordam aquelas temáticas. Tais práticas permitem a conversão dos saberes docentes mais formais em conteúdos mediados pelo professor de maneira a produzir sentido tanto teórico-conceitual como prático 
para o alunato. Porém, apesar de oportunizarem certo refinamento das técnicas de mediação pedagógicas para ensinar Sociologia aos alunos, as práticas de ensino de Sociologia chamadas aqui de propositivas náo geram, necessariamente, novos processos ou sistemas sociais organizacionais, mas a adoção de formatos menos convencionais para ministrar conteúdos de Ciências Sociais. Trata-se de melhorias modestas nos elementos individuais da tecnologia de ensino nas escolas, predominantemente pautada em componentes mais tradicionais como o uso do quadro e do giz, seminários, aulas expositivas e leitura de textos em sala de aula.

Sabemos que o manuseio das TICs como ferramentas para ministrar cursos, inclusive no nível médio, tem se constituído em prática didático-pedagógica recorrente para atrair a atenção do alunato e dinamizar o contexto de ensino e aprendizagem, como bem observa Silva (2013), ao tratar do uso do computador e dos telefones celulares conectados ou não à internet para ensinar Sociologia em escolas públicas do Distrito Federal. É fato que, para “inovar” em sala de aula utilizando as TICs como dispositivos pedagógicos no contexto de ensino, é preciso que tanto o professor quanto o aluno apresentem certo grau de inclusão digital, contando com capital tecnológico-informacional ${ }^{6}$ e com recursos materiais para o acesso a esses meios. Ou seja, é preciso certa simetria de disposiçóes para o uso instrutivo das tecnologias no ensino escolar entre docente - considerado um "migrante digital" - e alunato, visto como um "nativo digital" (BERALTO; BARBATO, 2013).

É preciso também atentar para as resistências que encontramos em contextos altamente institucionalizados de práticas docentes contra a adoção de inovações radicais ou incrementais, em termos schumpeterianos, (SCHUMPETER, 1961; 1985), quando se trata de conteúdos e formatos didático-pedagógicos. Do ponto de vista da Sociologia da Inovação (LATOUR, 2007), os sistemas educativos podem ser compreendidos como redes de atores cujos nós correspondem às diversas realidades em copresença: professores, alunos, pais, orientaçóes curriculares, disciplinas, formação dos professores, avaliação dos alunos, avaliação dos professores, avaliação do sistema, sindicatos e manuais. Podemos vislumbrar algumas dificuldades para a consolidação de práticas inovadoras para o ensino de Sociologia nas escolas. Esse sistema híbrido apresenta-se em configuraçóes estáveis perpassadas por fortes tradiçóes que tendem a se perpetuar, tornando os nós da rede reforçados mutuamente e resistentes a mudanças. (FIGUEIREDO, 2011).

No geral, esses futuros professores consideram a PE nas escolas uma provação importante para, sobretudo, repensarem a sua formação e a consolidação de seu engajamento no ensino médio como docente de Sociologia. As falas desses discentes do curso de Licenciatura em Ciências Sociais da Unb estão amparadas em operaçóes críticas advindas dos saberes docentes acumulados no percurso de instrução acadêmica ao qual tiveram acesso para se tornarem professores de Sociologia na escola. Nesse sentido, acreditamos que, devido ao valor pragmático e epis- 
têmico de tais relatos, esses profissionais são capazes de alterar o estado das coisas, porque têm caráter de denúncia contra as Ciências Sociais ministradas no ensino médio do Distrito Federal e introduzem na realidade novas referencialidades, novas racionalidades, novas lógicas de ação e novos conceitos ancorados no "mundo real", local em que se dá efetivamente o ensino de Sociologia. Os relatos de estágio trazem confirmaçóes e reaçóes aos pilares institucionais da Sociologia ensinada nas escolas do Distrito Federal, sendo portadores de reflexividade e subjetividades que se constroem na intersecção entre os saberes eas mediaçóes docentes e o princípio de realidade que a sala de aula lhes oferece.

\section{Considerações finais}

Podemos destacar algumas chaves de leitura fundamentais para refletirmos sobre os desafios e as perspectivas do ensino de Sociologia no Distrito Federal, levando em consideração a formação docente (licenciatura), os parâmetros curriculares, as práticas docentes e os contextos escolares. Evocamos o descompasso entre os dispositivos de normatização do ensino de Ciências Sociais na escola, o preparo instrucional do licenciando e a prática de ensino do docente, resultando na construção social dos saberes docentes que refletem essa assimetria. $\mathrm{O}$ acesso aos saberes docentes em Ciências Sociais manifestados em sala de aula e às representaçóes discentes repertoriadas neste texto,viabilizou a problematização acerca da formação do professor de Sociologia que atua no ensino médio no Distrito Federal. Tal procedimento de investigação nos permitiu ainda tratar a relação entre os conteúdos ministrados aos alunos, as orientaçóes curriculares e o contexto escolar local e o domínio — didático e conteudístico — de temas das Ciências Sociais pelo professor para atuar em sala de aula, em especial nos casos em que o responsável pela disciplina na escola não tem formação nessa área. Postulamos, então, três inferências principais decorrentes da nossa pesquisa.

A primeira constatação deriva dos conflitos latentes no processo de formação docente do licenciando que repercutem na sua condição futura de professor de Sociologia. Tais conflitos dizem respeito aos aspectos morais, éticos, institucionais, instrucionais e afetivos que, de algum modo, atuam no momento de tomada de decisão acerca dos conteúdos e da didática de cada docente em sua missão de ensinar Sociologia para jovens e adultos em contextos escolares diversos, perpassados por biografias e histórias de vida, em geral, não contemplados pelo nosso modelo de escola republicana. Tal cenário mais contribui para alargar as distâncias entre professor e alunato e entre os conteúdos das Ciências Sociais e a realidade dos sujeitos pertencentes a um dado contexto social do que para promover esclarecimentos e conscientização política, nos termos iluministas e civilizatórios dos propósitos destacados pelos próprios licenciandos em sua fase de formação instrucional. 
A segunda observação decorre das condiçóes materiais das escolas, especificamente das salas de aula, sobretudo de escolas públicas do Distrito Federal, assim como das capacidades sociocognitivas do alunato - principalmente no que se refere à EJA - em face às desigualdades de acesso e à quantidade e manutençáo de capital cultural desse público, dificultando a realização do ensino de Sociologia como disciplina formativa do ponto de vista humano e intelectual de certa forma apartada do modelo societal vigente.

A terceira averiguação decorre diretamente das duas formulações anteriores e refere-se às condiçóes de inovação em sala de aula para ministrar Sociologia no ensino médio no Distrito Federal, em função de dificuldades em romper com um conjunto de competências centrais alicerçadas em saberes docentes estruturados que dialogam com valores e normas rotinizados e cristalizados no seio da rede chamada sistema educacional. No entanto, foi também observado que, a partir das interaçóes entre professor, alunato e diferentes contextos sociais de ensino, tanto em escolas públicas quanto em escolas particulares do Distrito Federal, os docentes são capazes de produzir saberes que permitem a manifestação de singularidades expressas em atitudes propositivas no modo de ensinar a disciplina de uma maneira mais próxima da realidade social e cultural de seus estudantes e respectivos perfis, cada vez mais marcados pelo uso de TICs para acessar informaçóes e conhecimentos.

Entretanto, infere-se que a questão mais pertinente a considerar aqui é o preparo docente para harmonizar o uso da tecnologia ao propósito de conhecer e aprender a partir desse recurso, sem confundir meio e conteúdo ou fazer da tecnologia um fim em si mesma, o que comprometeria seu uso para fins didáticos e pedagógicos. Embora os usos de tecnologias para ministrar aulas de Sociologia não sejam objeto deste texto, trata-se de uma questáo com a qual se deparam professores do ensino médio, o que se constitui, sem dúvida, em um dos elementos para a formação docente para o ensino voltado a jovens e adultos na contemporaneidade. (SILVA, 2013). Além disso, essa discussão diz respeito à consideração acerca do perfil e das novas habilidades cambiantes do alunato da escola contemporânea.

Por fim, ao tratarmos das representaçôes dos licenciandos em Ciências Sociais da UnB acerca das práticas de ensino de Sociologia observadas durante seus estágios supervisionados nas escolas, acessamos seus saberes docentes e suas referências normativas expressos nessas representaçóes. Estas são reveladoras das expectativas, das concordâncias e dos desacordos que esses discentes manifestam em relação à Sociologia ministrada nas escolas quando confrontados com a realidade da prática docente em sala de aula. $\mathrm{O}$ trabalho normativo desses licenciandos, face aos dispositivos de normatização do ensino de Ciências Sociais nas escolas e à condução da disciplina feita pelo professor no contexto escolar, seja nas entrevistas ou expresso nos relatórios de estágio, forma insumo importante para a definição e redefinição de suas referências institucionais e curriculares em termos de saberes docentes e mediações pedagógicas. As operações críticas acerca das so- 
ciologias com as quais os licenciandos em Ciências Sociais se deparam em suas experiências docentes cotejadas até aqui redundam, quase sempre, em aspiraçóes de práticas docentes mais afinadas com suas perspectivas sobre a utilidade intelectual da disciplina, o conteúdo programático e o ensino de Ciências Sociais nas escolas. Assim, destacamos a essencialidade de ouvir nossos licenciandos sobre suas inquietaçôes existenciais enquanto futuros professores e suas experiências no curso de sua formação acadêmica se quisermos avançar no debate sobre saberes docentes e formação instrucional mais promissores para o ensino de Ciências Sociais na escola.

\section{Notas}

1. Nesse sentido, podemos citar dois programas governamentais implementados pelo Ministério da Educação brasileiro, durante os governos Lula e Dilma, focados na melhoria do ensino médio: o Pacto Nacional pelo Fortalecimento do Ensino Médio, voltado para a capacitaçáo em nível de especialização de professores das escolas públicas, e o Prodocência, dirigido para a consolidação dos cursos de licenciatura oferecidos por universidades brasileiras.

2. Segundo Lahire (2013, p. 21), "O ensino da sociologia, que eu desejaria pessoalmente possível, desde a escola primária, tem, a meu ver, um papel crucial para a vida coletiva e para a formação de cidadãos nas sociedades democráticas. Eu sustento que o ensino pedagogicamente adaptado da Sociologia desde a escola primária teria uma resposta adequada às exigências modernas de formação escolar dos cidadãos".

3. A noção de "repertório normativo" em Dodier e Barbot (2014; 2015) está referenciada na competência cognitiva de indivíduos ordinários capazes de realizar trabalhos normativos a partir de mediaçôes pelas quais dispositivos e humanos interagem. Nos termos dos autores, "Por trabalho normativo nós designamos, de uma maneira geral, as avaliaçóes positivas ou negativas que os indivíduos portam explicitamente sobre os estados de coisas" (DODIER, BARBOT, 2015, p. 92). A utilidade metodológica de operarmos em nossa pesquisa com a concepção de repertório normativo em face do próprio dispositivo de normatizaçáo do ensino de Sociologia nas escolas se relaciona com a essencialidade de discutirmos como o "trabalho normativo" dos atores sociais nos permite acessar as operaçóes críticas que os licenciandos exprimem ao avaliar os saberes docentes e as mediaçôes pedagógicas segundo suas expectativas normativas em relação à disciplina de Sociologia e seu ensino no espaço escolar.

4. Tal constatação dialoga com os trabalhos de Santos (2002), Rêses (2004) e Rodrigues (2007) ao discutirem estudos de casos no Distrito Federal.

5. Referenciamo-nos aqui naquilo que Boltanski (2008) chama de três gêneros de provações da ação e do discurso: provação de verdade, provação de realidade e provação existencial.

6. Tipo de capital cultural que informa capacidades e habilidades para uso das TICs de forma a contribuir para o compartilhamento e a criação de conhecimentos. (FREITAS, 2004). 


\section{Referências}

BALTAR, R. Mercado de trabalho para os sociólogos e a sociologia no ensino médio. 2015. Disponível em: <http://www.coletiva.org/site/index.phpoption=com k2\&view=item \&id=149:mercado-de-trabalho-para-os-soci \%C3\%B3logos-e-asociologia-no-ensino-m\%C3\%A9dio >. Acesso em: 17 ago. 2015.

BARDIN, L. Análise do conteúdo. Lisboa: Edições 70, 1977.

BERALDO, R.; BARBATO, S. Instrumentos pedagógicos para preparação e dinamização de aulas com o uso das TIC e da internet. Brasília: CEAD/UnB, 2013.

BOLTANSKI, L. Institutions et critique sociale: une approche pragmatique de la domination. Tracés Revue des Sciences Humaines, 2008. Disponível em: <https://traces. revues.org/2333>. Acesso em: 10 de out. 2012.

BORGES, C. Saberes docentes: diferentes tipologias e classificaçóes de um campo de pesquisa. Educação \& Sociedade, ano XXII, n. 74, abr.2001. Disponível em: < $\underline{\text { http://www. }}$ scielo.br/pdf/es/v22n74/a05v2274.pdf >. Acesso em: abr. 2012.

BOURDIEU, P. Questions de sociologie. França: Editions de Minuit, 1980. p. 264-268.

BRASIL. Ministério da Educação. Secretaria de Educação Média e Tecnológica. Orientaçôes Curriculares Nacionais para o Ensino Médio: Ciências Humanas e suas Tecnologias. Brasília: MEC/SEMTEC, 2006.

- Ministério da Educação. Secretaria de Educação Média e Tecnológica. Parâmetros Curriculares Nacionais: ensino médio. Brasília: MEC/SEMTEC, 1999.

.Ministério da Educação. Secretaria de Educação Média e Tecnológica. Parâmetros Curriculares Nacionais Mais: Ciências Humanas e suas Tecnologias. Brasília: MEC/ SEMTEC, 2002.

COSTA, W.R.; SOBREIRA, H.G. Do professor eterno ao complexo docente. In: ORTIGÃO, M.I.R. Educação: nas periferias urbanas. Rio de Janeiro: 7 Letras, 2011.

CHRISTENSEN, C.; HORN, M.; JOHNSON, C. Inovaçâo na sala de aula: como a inovaçâo de ruptura muda a forma de aprender. Porto Alegre: Artmed, 2009.

DODIER, N.; BARBOT, J. Face à l'extension des indemnisations non judiciaires. Le cas des victimes d'un drame de santé publique. Droit et société, n. 89, p. 89-103, 2015.

- Que faire de la compassion au travail? La réflexivité stratégique des avocats à

l'audience. SociologieduTravail, v. 56, n. 3, p. 365-385,jul./set. 2014.

DOUGLAS, M. Como as instituiçôes pensam. São Paulo: EDUSP, 1998.

FIGUEIREDO, A.D. Inovar em educação, educar para a inovação. In: FERNANDES, D. (Org.). Avaliação em educação: olhares sobre uma prática social incontornável. Pinhais: Melo, 2011. p. 13-28.

FRANCO, M.L.P.B. Análise de conteúdo. Brasília: Líber Livro, 2005. 
FREITAS, C. O capital tecnológico-informacional. Estudos de Sociologia, v. 8. n. 1.2, p. 163-183, 2004.

HANDFAS, A. A formação do professor de sociologia: reflexóes sobre diferentes modelos formativos. In: ; OLIVEIRA, L.F. (Orgs.). A sociologia vai à escola: história, ensino e docência. Rio de Janeiro: Quartet/Faperj, 2009.

HANDFAS, A.; MAÇAIRA, J.P. Dilemas e perspectivas da sociologia na educação básica. Rio de Janeiro: Faperj, 2012.

HANDFAS, A.; TEIXEIRA, R.C. A prática de ensino como rito de passagem e o ensino de sociologia nas escolas de nível médio. Mediaçôes, Londrina, v. 12, n. 1, p. 131-142, jan./jun. 2007.

HANDFAS, A. et al. (Orgs.). A sociologia vai à escola: história, ensino e docência. Rio de Janeiro: Quartet/Faperj, 2009.

LAHIRE, B. À quoi sert la sociologie?Paris: La Découverte, 2004.

. L'esprit sociologique. Paris: La Découverte, 2007.

. Viver e interpretar o mundo social: para que serve o ensino de sociologia? In: GONÇALVES, D.N. (Org.). Sociologia e juventude no ensino médio: formação, Pibide outras experiências. Campinas: Pontes, 2013.

LATOUR, B. Changer de société, refaire de la sociologie. Paris: La Découverte, 2007.

MORAES, A.C. Desafios para a implantação do ensino de sociologia na escola média brasileira. In: HANDFAS, A. et al. (Orgs.). A sociologia vai à escola: história, ensino e docência. Rio de Janeiro: Quartet/Faperj, 2009.

MORAN, J.M.; MASETTO, M.T.; BEHRENS, M.A. Novas Tecnologias e mediação Pedagógica. Campinas: Papirus, 2013.

OLIVEIRA, A.P. Ensino de Sociologia: desafios epistemológicos para o ensino médio. Espaço Acadêmico, n. 119, abr. 2011. Disponível em: <http://www.periodicos.uem. br/ojs/index.php/EspacoAcademico/article/viewFile/11758/6865>. Acesso em: 12 set. 2013.

OLIVEIRA, L.C.; SOBREIRA, H.G. Representaçôes sobre religiōes afro-brasileiras na formaçáo de professores. In: ORTIGÁO, M.I.R. Educação: nas periferias urbanas. Rio de Janeiro: 7 Letras, 2011.

RÊSES, E.S. E com a palavra: os alunos: estudo das representaçóes sociais dos alunos da rede pública do Distrito Federal sobre a Sociologia no ensino médio. 2004. Dissertação (Mestrado em Sociologia). Programa de Pós-graduação do Departamento de Sociologia. Universidade de Brasília, Brasília.

RODRIGUES, S.D. Cidadania e espaço público a partir da escola: resgate, recriação ou abandono? 2007. Dissertação (Mestrado em Sociologia). Departamento de Sociologia. Universidade de Brasília, Brasília. 
SANTOS, M.B. A Sociologia no Ensino Médio: o que pensam os professores da rede pública do Distrito Federal. 2002. Dissertação (mestrado em Sociologia). Instituto de Ciências Sociais. Universidade de Brasília, Brasília.

SCHUMPETER, J. Capitalismo, socialismo e democracia. Rio de Janeiro: Fundo de Cultura, 1961.

Teoria do desenvolvimento econômico.São Paulo: Nova Cultural,1985.

SILVA, J. As tecnologias da informação e da comunicação e o ensino de Sociologia nas escolas públicas do Distrito Federal: inclusão digital e capital tecnológico-informacional. 2013.Dissertação (mestrado em Sociologia).Programa de Pós-graduação em Sociologia. Universidade de Brasília, Brasília.

SOUSA, D.T.; REGHIM, M.S.; GOMES, A.F. A formação de professores de sociologia: o debate sobre os modelos formativos e algumas hipóteses de pesquisa. In: ENSOC, 3., 28 a 30 set. 2012. Anais...Rio de Janeiro, 2012. Disponível em: <http://www.labes.fe.ufrj.br/ Eventos/3ENSOC/PDF/GT2.3.2.pdf>. Acesso em: 21 de mar. 2014.

Recebido em 25 de junho de 2015.

Aprovado em 01 de novembro de 2016. 